\title{
Research on the Path of Implicit Ideological and Political Education for Chinese Youth
}

\author{
Yingxuan Yang* \\ School of Marxism, Northwestern Polytechnical University, Xi'an, 710072, P. R. China \\ *Corresponding author. Email: yangyingxuan@mail.nwpu.edu.cn
}

\begin{abstract}
As an important place for contemporary youth activities, the network environment is flooded with complex and diverse network information content. Young people's public personality leads to their unethical speech on the Internet because their ability to distinguish right from wrong has not been developed. Based on the analysis of the characteristics of contemporary college teenagers, this article believes that the ideological and political education of our country's adolescents should give play to the educational function of college workers, the guiding role of media workers and the positive influence of family members, and incorporate correct ideological concepts into the study and life of young people, and give play to the value of implicit ideological and political education in schools, families, and society.
\end{abstract}

Keywords: Implicit ideological and political education, Educational function, Guiding role, Positive influence.

\section{INTRODUCTION}

With the rapid development of network information today, the concealment of the Internet has provided convenience to some people who violate the laws and ethics of the Internet. They use the timeliness and extensiveness of information dissemination to give contemporary teenagers the wrong direction. Contemporary young people are active in thinking, quick in thinking, novel in concepts, broad in interests, and full of enthusiasm for exploring the unknown. Various online social platforms have become "microphones" for contemporary youth to express their views in a timely manner. The complex network environment and the uneven network culture have brought great challenges to colleges and universities to correctly guide and cultivate young people. General Secretary $\mathrm{Xi}$ Jinping emphasized at the National Conference on Propaganda and Ideological Work: "It is necessary to grasp the critical period of formation and determination of young people's values, and guide them to hold the first button in their lives. Implicit ideological and political education is a new mode in the process of ideological and political education for young people. It is a method of educating, guiding, and influencing people subtly, so that the educatee can gain some kind of thought or experience unconsciously. The recessive ideological and political education model which aims at the characteristics of young people's subjective consciousness and strong sense of participation conforms to the contemporary university education model, allowing the subject to consciously accept the object value requirements, and give full play to the realistic value of recessive ideological and political education in our country's ideological education. According to the law of learning and growth of contemporary young people, this article makes use of implicit ideological and political education to make the educatee readily accept it, and realize the morality and the cultivation of people silently.

\section{GIVE FULL PLAY TO THE EDUCATION FUNCTION OF UNIVERSITY WORKERS}

At present, in society with active ideas, collisions of ideas, and new technologies and media such as the Internet, Chinese teenagers are willing to express their thoughts in various forms of We-Media. As implementation basis of implicit ideological and political education is the school, it is necessary for college workers to strengthen the combination of implicit ideological and political education and explicit ideological and political education, so as to make 
contributions to the ideological and political education in our country's universities. Faced with the asymmetry of information in the online world and the concealment of the Internet, young people are more confident and emphasize individuality, are willing to share their stories, and dare to express their own interests and opinions, which leads to the intrusion of diversified thoughts hinders the ideological and political education work of our country's colleges and universities, and affects the development of our country's youth values. University workers should formulate different measures to carry out implicit ideological and political education for students according to the growth and learning laws of students, so that young people with public personality will cultivate and cultivate young students to establish lofty ideals and deep family and country feelings while learning knowledge.

\subsection{Coordinate the Promotion of Curriculum Education}

The intrusion of diversified thoughts in today's society will affect students' value judgments. Facing the complex social environment, university educators are responsible for enlightening the thoughts, cultivating sentiments, and warming the soul. The goal of our country's curriculum is not only to equip students with knowledge, but also to cultivate ethical individuals. Not only has the responsibility of teaching and educating people, but also nurturing young students to establish lofty ideals and deep family and country feelings. The purpose is to let students know what is right, be able to define good values, establish reasonable moral principles, and explain what good character is and correct behavior. Therefore, the curriculum of our country's universities should focus on cultivating the following skills as the standard. Students need to master moral reasoning, critical thinking, responsible decision-making, problem-solving, effective communication, and the opportunity to practice good values. New courses for students of different ages should be set up through the above goal of nurturing students. Teachers in colleges and universities should establish a variety of teaching methods, using a variety of popular and common methods, including education in construction achievements, education in entertainment, education in literature, and education in travel, etc., to integrate ideological and political education, so that young students can receive education unconsciously.

\subsection{Continuously Deepen Service and Education}

Convince people with reason and cultivate people with equal communication between emotional people. The entry point of the implicit ideological and political education is that students are learning the details and events of life. Students will face various ideological, political, and moral problems and confusions in social life, and they can seek for analysis through the implicit ideological and political education. According to the characteristics of contemporary students, we formulate management countermeasures, thinking that we should respect differences and individuality; guide students to cultivate the habit of reasonable planning, establish the habit of safety awareness, and the habit of teamwork; teachers should communicate with students on an equal footing. Teachers in colleges and universities should always insist on taking the educatee as the main body, and make the educatee unconsciously accept and understand in a relaxed and happy state. It is necessary to introduce a personalized education system, break the traditional learning framework, pay attention to the cultivation of value and the improvement of personality, so that students can learn knowledge and harvest wisdom in a relatively free and comfortable environment, and truly cultivate good and qualified students who have ideals, morals, culture, and discipline for the socialist modernization drive.

\subsection{Further Promote Cultural Education}

The educational purpose of the various educational activities in the construction of campus culture is to strengthen student behavior standards and provide a standard for the development of students' moral quality and the implementation of personal behavior. The purpose of setting standards is to regulate students' daily behaviors and deepen the impact of campus culture on students and give full play to the subtle educational work of campus culture, to create a good ideological and political education atmosphere. A good cultural atmosphere in campus is a necessary condition for the success of our ideological and political education in colleges and universities. Without a good ideological, cultural and moral atmosphere, students are bound to be unable to form good moral habits. Therefore, the school level should strengthen the construction of school spirit, study style, and teacher style in the future works. At the social level, we must also take active actions and advocate integrity, so as to create a good ideological environment for students. In the construction of campus culture, the school will post the deeds of advanced characters in the campus information column, so that students can see these content every day, and subtly influence students' thoughts and behaviors. And ideological and political education can make full use of this advantage of campus culture construction, update teaching methods, strengthen the education of students' values, and make students become high-quality talents. 


\section{GIVE PLAY TO THE POSITIVE GUIDING ROLE OF MEDIA WORKERS}

Entering the highly-developed information age of the mobile Internet, the communication field of new media has expanded rapidly. The waning group tension, diverse opinions, information distortion and the clamor of sentient beings have invisibly aggravated the differentiation of young people's ways of thinking and the weakening of common value orientation. Therefore, it is necessary to strengthen efforts to utilize the external environment and use new media and news propaganda teams to spread positive energy, so as to realize the real value of implicit ideological and political education in the growth of young people's lives.

\subsection{Use the News Propaganda Team to Guide Students to Establish a Correct Outlook on Life, World Outlook and Values}

As the formation of young people's world outlook, outlook on life, and values are not incomplete, media propaganda workers should summarize the rules of misdirection and prevent and control misguided public opinion, thereby reducing the difficulty of ideological and political work in universities. Therefore, the news team should classify different types of news dissemination content according to the characteristics of young people, and categorize the students' love for news in recent years, and mainly establish a dissemination content that is mainly politically oriented, supplemented by ideological and consumption-oriented. Promote the construction of political values of college students. Through implicit ideological and political education, students are guided to participate in real political life in a rational and orderly manner, so that students can grow up healthily and form and internalize political values.

\subsection{Media Workers Must Continue to Learn and Transfer Positive Energy to Educate People}

As teenagers are easily influenced by different ideas in the complex and diverse cyberspace, the positive nature of online media content should be strengthened. The media work team needs to grasp the overall situation, understand the facts, and pay attention to art, so that the news team can convey the correct direction of public opinion. We should improve the guidance of news and public opinion; grasp the timeliness of hot issues and emergencies to achieve the role of positive publicity and guidance. The work of news and public opinion should be based on consensus building, and strive to give an authoritative and accurate voice at the first time, and adhere to the correct guidance of public opinion, make accurate decisions, and achieve the ideal publicity effect, so that when students receive the first information accurately, they can influence students to make correct value judgments. The correct orientation of these cyberspaces is to guide students to form a good character and become an intermediate force that contributes to society.

\subsection{Use New Media to Guide People Imperceptibly}

WeChat and Weibo are important carriers of ideological education in the all-media era. Public opinion propaganda has the role of timely and effective ideological education. The use of WeChat to spread positive energy requires respect for the main role of students, practice full-staff education, and encourage front-line teachers, experts and scholars to take the initiative to speak out on the Internet. Information dissemination on Weibo should abide by the principle of socialism; the principle of content penetration in ideological and political education should be observed; the main principle of emphasizing the status of college students as the main body of the network; the demonstration principles to play the role of celebrity microblog users as role models. Thanks to the correct guidance of new media, students will pay more attention to caring for others in the family, school, community, country and the world. New media communication must firmly grasp the laws of contemporary young people's thoughts and behaviors, and use correct public opinion guidance to spread positive energy.

\subsection{The Content of Network Communication Should Put Social Benefit In the First Place}

Dissemination of excellent hot content that is beneficial to society, because it not only can achieve ideological success, but also can be popular with the public in the network environment. Promote the correct multiculturalism ideology disseminated in cyberspace and transform the concept of the country into the political outlook, values and morals of citizens. The dissemination of correct values in cyberspace can guide students to distinguish right from wrong, help them make responsible decisions, and recognize their role in society. In the dissemination of ideas and contents in the network environment, when two benefits and two values contradict each other, economic benefits should be subordinated to social benefits and market values to social values. Only in this way can we adhere to the correct guidance of public opinion and promote positive social energy. At the same time, it is necessary to strengthen cyberspace governance in accordance with the law, strengthen the construction of online content, strengthen positive online publicity, cultivate a positive, healthy, and upward-oriented online culture, and use socialist core values as well as outstanding human 
civilization achievements to nourish people's hearts, achieve ample positive energy and high main theme, and create a clean and upright network environment for the majority of netizens, especially young people.

\section{EXERT THE POSITIVE INFLUENCE OF FAMILY MEMBERS}

As the starting point of children's growth education, family is the basic unit of the society. The quality of integrity helps individuals build trust in the family, and tenacity enables individuals to take responsibility when facing setbacks and crises. Therefore, parents who are the starting point of their children's education must always pay attention to their children's learning and psychological dynamics, so that children can establish a correct outlook on the world, life, values, ethics and politics as they grow up.

\subsection{Family Members should Integrate Patriotism Education into the Study and Life of Young People}

In the process of children's growth, patriotism education should be taken as a prominent content, from the love of people around to the love of the region and the nation. Such cohesion makes patriotism education more solid and more deeply rooted in the hearts of the people, so as to cultivate the strong sense of identity for the country and the nation of young people. First of all, young people's understanding of traditional culture, their love for the countryside and the cultivation of national spirit. Secondly, strengthen the mentality of the youth's national identity. National identity is the psychological belief that oneself belongs to the political community of the country, and the psychological recognition of oneself as a member of the country. The resulting cohesive emotions make citizens willing to actively work for the common life, and willing to sacrifice themselves when the community is in danger.

\subsection{Family Members should Strengthen Individual Moral Education for Young People}

The purpose of this education is to fully develop the personality, and strive to train young students who are physically and mentally healthy, so that they can become builders of a peaceful society and country that love truth and justice, respect personal values, respect labor, have a strong sense of responsibility and are full of independence spirit. Family members should focus on cultivating and training students to have good moral character and civilized behavior habits, and educate students to care about others, the collectivity, the people, and the motherland.

\section{CONCLUSION}

If the young generation has ideals, the country will have hope. The young generation loves the motherland, and the country has power. Facing contemporary young people who are active in their thinking and have a strong desire for life development, implicit ideological and political education is in line with the new way of educating people in contemporary universities. Implicit ideological and political education has multi-dimensional values such as cognition, aesthetics, development, and culturalization of people. Its development is to avoid the lack of one-way education and make it more attractive through the implementation of hidden ideological and political education process, such as rendering, language incentive transmission, activity teaching infiltration, etc. According to the growth law of contemporary young people, strengthen the educational synergy of college teachers, media workers and family members, so that the educated can subtly accept various forms of education to convey educational content, and truly realize the purpose of moisturizing things silently.

\section{REFERENCES}

[1] Xi Jinping's comments on state administration, Volume 3 [M]. Beijing: Foreign Languages Press, 2020. DOI: http://www.flp.com.cn

[2] Feng Gang. Ideological and political education research hotspot annual release 2019[M]. Beijing: Unity Press, 2020. DOI: http://www.tjpress.com

[3] Hu Daping. Adhere to the unification of explicit education and implicit education, and comprehensively improve the level of morality and talent cultivation in universities $[\mathrm{J}]$. Ideological and Theoretical Education Guide, 2019, (07). DOI: https://doi.org/10.16580/j.sxlljydk.2019.07.018 